\title{
Aquatic transitions in Southeast Asia and Oceania
}

\author{
Keely Mills', S. McGowan², É. Saulnier-Talbot ${ }^{3}$ and P. Gell ${ }^{4}$ \\ Kuala Lumpur, Malaysia, 15-17 February 2017
}

The first two meetings of the Aquatic Transitions working group, whilst focused on a global agenda, were dominated by members from Europe and North America. Early screening of metadata available from these members highlighted major data gaps in China, South America, Africa, and Tropical Asia. To address some of these gaps, Aquatic Transitions "piggy-backed" on a number of international conferences in China (International Paleolimnology Symposium, Lanzhou, August 2015; INTECOL Wetlands Conference, Changshu, September 2016) to raise our profile and recruit potential members from Asia. This third meeting focused efforts in SE Asia, and welcomed 30 participants (20 from Tropical Asia) to Kuala Lumpur. The group comprised six Aquatic Transitions "veterans", eight established academics with expertise in the region, eight early-career researchers, seven MSc and PhD students, and a stakeholder from the Forestry Research Institute of Malaysia.

Given the new group composition, day one began with introductions to PAGES and Aquatic Transitions, and to what we thought we knew about lake systems in the tropical Asia region, summarizing previously published work (Fig. 1). All participants gave "speed talks", introducing themselves, their research, and the lake systems on which they worked. The afternoon closed with a short lecture on "what is paleolimnology" for those who were less familiar with its use and application.
On the second day, participants rotated between six discussion groups focused on the key topics: SE Asia regional review; Ecosystem services; Linking lakes and drivers; Paleoproblem solving; Lakes as socio-ecological systems; and Freshwater biodiversity. In the afternoon, participants were updated on outputs from the previous Aquatic Transitions meetings (with a focus on populating the UCL-hosted LakeCores database), published papers and those in preparation, and a "Developments in Paleoenvironmental Research" volume that was solicited by Springer. During this session, a number of abstracts were prepared as part of the book proposal - with contributions from early-career members. As part of the database activities, data and publications from the Tropical Asia region were compiled during the meeting (Fig. 1). The day ended with a public lecture hosted by University of Nottingham's Malaysia Campus as part of the Mindset Research Centre lecture series. Three short lectures were delivered by Keely Mills, Nathalie Dubois and Suzanne McGowan under the title "Understanding the Anthropocene using lake sediment records". The talk attracted over 80 attendees and is available as a podcast here: http://mindset.my/content/talk021.html

The final day focused on stakeholders and regional engagement and capacity building. As Aquatic Transitions moves forward, and in an attempt to have our outputs utilized outside academia, it is important to identify key stakeholders. Small groups mapped stakeholder groups, categorizing those who have a high level of interest in our work, and those who have a high level of influence. This was a productive exercise to think more broadly about our interactions when designing research projects for impact. The meeting concluded with discussions on the next steps for Aquatic Transitions - the initial three-year phase ends in December 2017. Community interest was gauged to assess whether we should apply for a second phase to allow us to include more researchers from regions that lack data. Attendees at the Tropical Asia workshop provided excellent support, and it has been agreed that whilst we tie up Phase 1 loose ends, we submit an application in early 2018 for Phase 2. Future workshops in Africa and South America would boost interest and encourage global participation. Finally, regional leaders to help drive Phase 2 forward were identified.

\section{AFFILIATIONS}

'British Geological Survey, Keyworth, UK 2School of Geography, University of Nottingham, UK Université Laval, Québec, Canada

${ }^{4}$ Water Research Network, Federation University Australia, Ballarat, Australia

CONTACT

Keely Mills: kmil@bgs.ac.uk

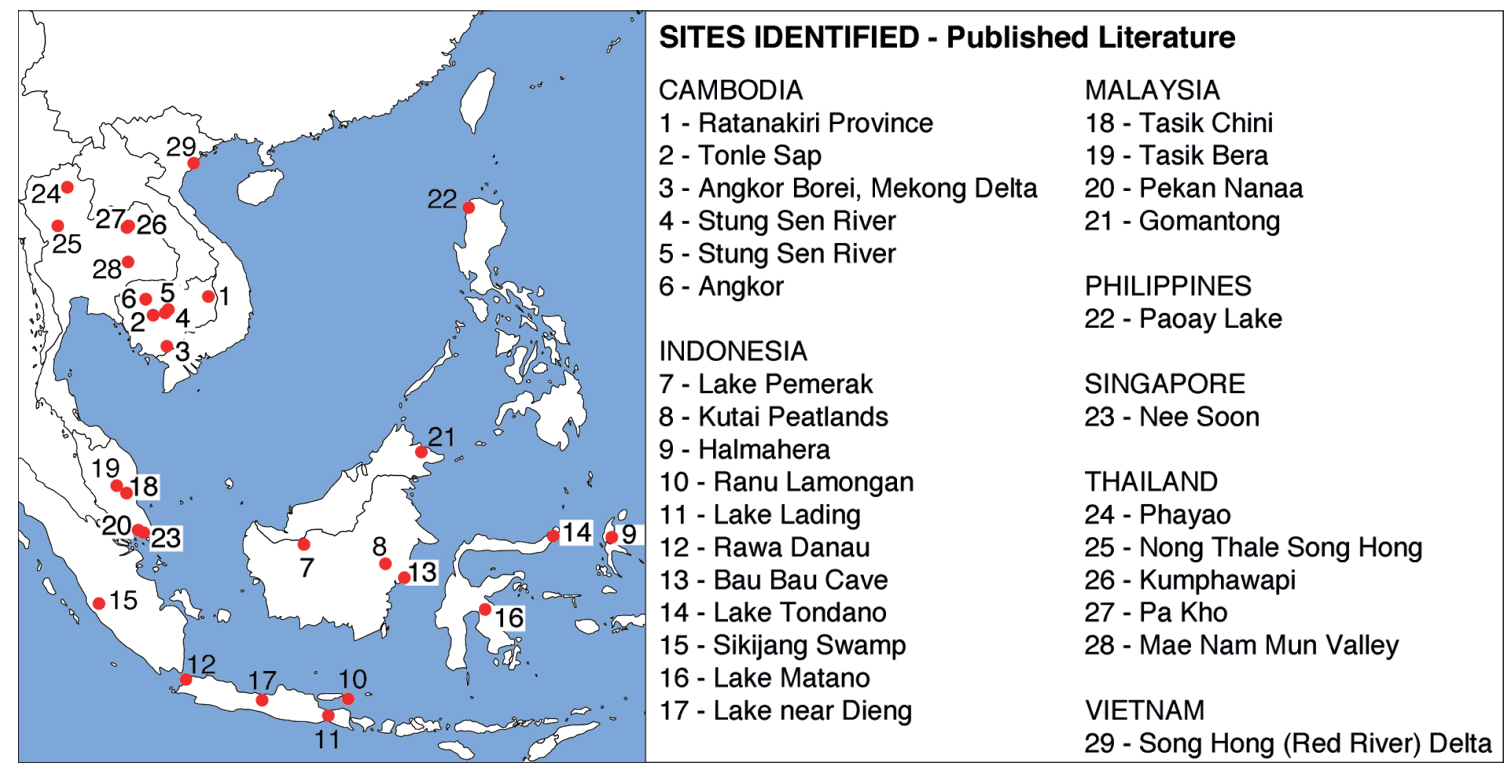

Figure 1: During the workshop, we compiled a list of published paleolimnological research from across the south east Asia region. We are now in the process of synthesizing this data into a paper titled "Paleoenvironmental change from SE Asian lacustrine sites". 